\title{
Glutamate Decarboxylase 67 Deficiency in a Subset of GABAergic Neurons Induces Schizophrenia-Related Phenotypes
}

\author{
Kazuyuki Fujihara' ${ }^{1,2,3,6}$, Hideki Miwa ${ }^{*, 1,2,6}$, Toshikazu Kakizaki ${ }^{1,2}$, Ryosuke Kaneko',2,4, Masahiko Mikuni ${ }^{3}$, \\ Chiyoko Tanahira ${ }^{5}$, Nobuaki Tamamaki ${ }^{5}$ and Yuchio Yanagawa ${ }^{1,2}$ \\ 'Department of Genetic and Behavioral Neuroscience, Gunma University Graduate School of Medicine, Maebashi, Japan; ${ }^{2}$ Core Research for \\ Evolutional Science and Technology (CREST), Japan Science and Technology Agency (IST), Tokyo, Japan; ${ }^{3}$ Department of Psychiatry and Human \\ Behavior, Gunma University Graduate School of Medicine, Maebashi, Japan; ${ }^{4}$ Institute of Experimental Animal Research, Gunma University \\ Graduate School of Medicine, Maebashi, Japan; ${ }^{5}$ Department of Morphological Neural Science, Graduate School of Medical Sciences, Kumamoto \\ University, Kumamoto, Japan
}

\begin{abstract}
Decreased expression of the GABA synthetic enzyme glutamate decarboxylase 67 (GAD67) in a subset of GABAergic neurons, including parvalbumin (PV)-expressing neurons, has been observed in postmortem brain studies of schizophrenics and in animal models of schizophrenia. However, it is unclear whether and how the perturbations of GAD67-mediated GABA synthesis and signaling contribute to the pathogenesis of schizophrenia. To address this issue, we generated the mice lacking GAD67 primarily in PV neurons and characterized them with focus on schizophrenia-related parameters. We found that heterozygous mutant mice exhibited schizophrenia-related behavioral abnormalities such as deficits in prepulse inhibition, MK-80I sensitivity, and social memory. Furthermore, we observed reduced inhibitory synaptic transmission, altered properties of NMDA receptor-mediated synaptic responses in pyramidal neurons, and increased spine density in hippocampal CAI apical dendrites, suggesting a possible link between GAD67 deficiency and disturbed glutamatergic excitatory synaptic functions in schizophrenia. Thus, our results indicate that the mice heterozygous for GAD67 deficiency primarily in PV neurons share several neurochemical and behavioral abnormalities with schizophrenia, offering a novel tool for addressing the underlying pathophysiology of schizophrenia.

Neuropsychopharmacology (20I5) 40, 2475-2486; do::I 0.I 038/npp.20 I 5.I I7; published online 20 May 20 I5
\end{abstract}

\section{INTRODUCTION}

Schizophrenia is a major psychiatric disorder and is characterized by three classes of signs and clinical symptoms: positive symptoms (auditory hallucinations, delusions, and disorganized speech); negative symptoms (blunted affect and social withdrawal); and cognitive dysfunctions (Braff et al, 2001; Couture et al, 2006; Piskulic et al, 2007). Recent studies have revealed that schizophrenia develops through complex interactions between multiple genes and environmental risk factors (Insel, 2010). However, because of the etiological heterogeneity of schizophrenia, the molecular and cellular mechanisms in schizophrenia pathogenesis remain largely unknown. Thus, it is important to identify a common pathway that contributes to schizophrenia pathogenesis.

*Correspondence: Dr H Miwa, Department of Genetic and Behavioral Neuroscience, Gunma University Graduate School of Medicine, Maebashi 37|-85II, Japan, Tel: +8I 27220 8044, Fax: +8I 27220 8046, E-mail: hmiwa@gunma-u.ac.jp

${ }^{6}$ These authors contributed equally to this work.

Received 18 February 2015; revised 5 April 2015; accepted 7 April

2015; accepted article preview online 23 April 2015
One of the most consistent findings in postmortem brain studies of schizophrenics is the decreased expression of the $67-\mathrm{kDa}$ isoform of glutamate decarboxylase (GAD67), the primary GABA-synthesizing enzyme, in a subpopulation of GABAergic neurons (Guidotti et al, 2000; Hashimoto et al, 2003, 2008; Volk et al, 2000) including parvalbumin (PV)expressing cells (Hashimoto et al, 2003) and somatostatin (SST)-expressing cells (Hashimoto et al, 2008) in the cerebral cortex and hippocampus. Similar GAD67 reductions have been observed in different animal schizophrenia models including NMDA receptor hypo-functioning in mice and the dopamine sensitization model in rats (Behrens et al, 2007; Lee et al, 2013; Liu et al, 2001; Takao et al, 2013). These studies suggest that GABAergic neuron dysfunction, primarily in PV neurons, is involved in schizophrenia pathophysiology, and this dysfunction may be a common process of the disease even though the etiology is heterogeneous. However, it is unknown whether the alteration is a cause of schizophrenia-related symptoms or merely an effect of the disease process.

Here, we report the generation and analyses of a conditional GAD67-knockout mouse strain in which GAD67 is 
deleted in a subset of GABAergic neurons, primarily in PV neurons, to address the cause and effect relationship between GAD67 deficiency and schizophrenia pathogenesis. We found that haploinsufficiency of the GAD67 gene in a subset of GABAergic neurons induced schizophrenia-related behavioral phenotypes and synaptic dysfunction in the hippocampus. Therefore, our results support the hypothesis that GAD67 deficiency is a possible common pathway that contributes to schizophrenia pathogenesis.

\section{MATERIALS AND METHODS}

A detailed description of the Materials and Methods is provided in the Supplementary Information.

\section{Animals}

PV-Cre; GAD67 flox/flox and PV-Cre; GAD67 flox/+ mice were generated by crossing Pvalb-Cre BAC transgenic (Tg(Pvalb-cre); hereafter, PV-Cre) mice (Tanahira et al, 2009) and GAD67-floxed (Gad1 ${ }^{\text {TmI }}$ ) mice (Obata et al, 2008). In behavioral tests and acute slice electrophysiology, male $P V$-Cre; GAD67 flox/+ mutant mice and littermate male controls $\left(G A D 6 f^{f l o x /+}\right)$ were used. All experiments were performed in accordance with the guidelines of the Animal Care and Experimentation Committee of the Gunma University and the Animal Research Committee of the Kumamoto University. All efforts were made to minimize the number of animals used and their suffering.

\section{Western Blot Analysis}

A standard Western blotting procedure was performed as described in the Supplementary Information, using antiGAD65/67 $(1 \mu \mathrm{g} / \mathrm{ml})$ and anti- $\beta$-actin antibody $(1: 10000$, Abcam). Protein levels were quantified by densitometry of the immunochemical signal using Image software and normalized to the signal intensity obtained for $\beta$-actin.

\section{Immunohistochemistry}

Perfusion and immunohistochemistry were performed as described in the Supplementary Information, using rabbit anti-PV antibody ( $1: 5000$, Swant), mouse anti-PV $(1: 5000$, Swant), monoclonal mouse anti-GAD67 antibody ( $1: 1000$, Millipore), rabbit anti-GABA (1:1000, Sigma), rabbit anticalretinin $(1: 2000$, Swant), and rabbit anti-SST-14 $(1: 2000$, Peninsula Laboratories). To visualize perineuronal nets (PNN), brain sections were incubated with the biotinylated lectin Wisteria floribunda agglutinin $(1: 2000$, Vector Labs) at $4{ }^{\circ} \mathrm{C}$ overnight. After washing in PBS, the sections were incubated with Alexa Fluor 594 conjugated to streptavidin for $20 \mathrm{~min}$ at room temperature. For quantitative analysis, images were captured with a confocal laser scanning microscope (FV1000, Olympus) for GAD67, PV, calretinin, and SST or with a conventional epifluorescence microscope for GABA and PV double staining. The images were analyzed using ImageJ software. For each brain slice, all PV-, GAD67-, or GABA-positive cells were visually identified, and the intensities of the immunoreactive signals from the cell somata of each slice were measured. For GABA and PV double immunohistochemistry, the signal intensities were measured and then transformed into $Z$-scores using the mean and SD of the control mice to equalize the variability of the immunohistochemical staining among the different samples due to differences in anti-GABA antibody penetration. Quantification of the fluorescent intensities was carried out without any adjustment of brightness/contrast. Stereological cell counting approach was employed from rectangular regions-of-interests (ROIs) of fixed size positioned over the prefrontal cortex $(1000-\mu \mathrm{m}$ high $\times 500-\mu \mathrm{m}$ wide $)$. Fluorescent cells within each ROI were counted using the Cell Counter plugin for ImageJ.

\section{Slice Preparation and Electrophysiology}

Hippocampal slices were prepared from 12- to 16-week-old male PV-Cre; GAD67flox>+ mice and littermate controls $\left(\right.$ GAD6f $f^{f l o x /+}$ ), using standard procedures (Miwa et al, 2008). Slices were perfused with a medium that was saturated with $95 \% \quad \mathrm{O}_{2}$ and $5 \% \quad \mathrm{CO}_{2}$ and contained $119 \mathrm{mM}$ $\mathrm{NaCl}, 2.5 \mathrm{mM} \quad \mathrm{KCl}, 2.5 \mathrm{mM} \mathrm{CaCl}, \quad 1.3 \mathrm{mM} \mathrm{MgSO}_{4}$, $1.0 \mathrm{mM} \mathrm{NaH}_{2} \mathrm{PO}_{4}, 26.2 \mathrm{mM} \mathrm{NaHCO}_{3}$, and $11 \mathrm{mM}$ glucose. The medium (at $25 \pm 1{ }^{\circ} \mathrm{C}$ ) for recordings containing $100 \mu \mathrm{M}$ picrotoxin, a $\mathrm{GABA}_{\mathrm{A}}$ receptor antagonist, was used for all of the experiments except for the recording of $G_{A B A}$ receptor-mediated inhibitory postsynaptic currents $\left(\mathrm{GABA}_{\mathrm{A}}\right.$-IPSCs). Whole-cell patch-clamp recordings were made from pyramidal cells in the CA1 region with a MultiClamp 700B patch-clamp amplifier (Molecular Devices, Union City, CA, USA). The pipette solution contained $122.5 \mathrm{mM}$ cesium gluconate, $17.5 \mathrm{mM} \mathrm{CsCl}, 10 \mathrm{mM}$ HEPES, $0.2 \mathrm{mM}$ EGTA, $8 \mathrm{mM} \mathrm{NaCl}, 2 \mathrm{mM} \mathrm{Mg}$-ATP, and $0.3 \mathrm{mM}$ $\mathrm{Na}_{3}$-GTP ( $\mathrm{pH} 7.2 ; 290-310 \mathrm{mOsm}$ ). In some experiments, biocytin $(5 \mathrm{mg} / \mathrm{ml})$ was added to the internal solution immediately before recording. The recording electrodes had resistances of 3-7 M $\Omega$. The series resistance was 10-30 M $\Omega$ and was monitored online throughout the experiment. The experiments were rejected if the series resistance changed by $>20 \%$. The signal was filtered at $5 \mathrm{kHz}$ and digitized at $20 \mathrm{kHz}$ with pClamp9.2 software (Molecular Devices). For evoking synaptic responses, a bipolar stimulating electrode was placed in the stratum radiatum and was stimulated at $0.1 \mathrm{~Hz}$. The cells were voltage clamped at $-90 \mathrm{mV}$ to record excitatory postsynaptic currents (EPSCs), unless otherwise indicated. When NMDA receptor-mediated EPSCs were recorded, $10 \mu \mathrm{M}$ CNQX was present to block AMPA receptor-mediated EPSCs (AMPA-EPSCs). GABA APSCs $^{-I P}$ were evoked at $0 \mathrm{mV}$ in the presence of CNQX $(10 \mu \mathrm{M})$ and D-APV $(50 \mu \mathrm{M})$. Experiments were carried out in a genotype-blinded manner.

\section{Dendritic Spine Measurements}

CA1 pyramidal neurons were filled with intracellular solution containing biocytin for at least 5-10 min, and then fixed. Biocytin was visualized with Alexa Fluor-594streptavidin. Serial Z-stack images of secondary apical dendritic segments were obtained by confocal microscopy (Olympus FV1000 Fluoview confocal microscope; $\times 100$ oil immersion objective (NA 1.4); $5.0 \times$ zoom). The digitized stack images were deconvolved with AutoQuant X3 (Media Cybernetics, Rockville, MD, USA) and then analyzed using 
Fiji (ImageJ) software. The number of spines was counted manually and spine density was calculated.

\section{Behavioral Analyses}

Open field test. Each mouse was placed in one corner of the apparatus (O'Hara, Tokyo, Japan) and was allowed to move freely for $30 \mathrm{~min}$ and then MK-801 (0.2 mg/kg; Sigma) was administered intraperitoneally, and the mouse was returned to the same arena for $90 \mathrm{~min}$. Data were collected every $5 \mathrm{~min}$ and analyzed using Image OFC software (O’Hara).

Acoustic startle response and PPI test. An acoustic startle reflex measurement system (O'Hara) was used. The startle response was assessed with various stimuli intensities. Five times of 70 to $120 \mathrm{~dB}(70,75,80,85,90,95,100,110$, and $120 \mathrm{~dB}$ ) white noise stimuli (40 ms) were presented in quasirandom order and random inter-trial intervals (10-20 s). In the prepulse inhibition (PPI) session, mice experienced five trial types: no stimulus; startle stimulus (120 dB, $40 \mathrm{~ms}$ ) only; prepulse $70 \mathrm{~dB}(20 \mathrm{~ms}$, lead time $100 \mathrm{~ms})$ and pulse $120 \mathrm{~dB}$; prepulse $75 \mathrm{~dB}(20 \mathrm{~ms}$, lead time $100 \mathrm{~ms})$ and pulse $120 \mathrm{~dB}$; and prepulse $80 \mathrm{~dB}(20 \mathrm{~ms}$, lead time $100 \mathrm{~ms})$ and pulse $120 \mathrm{~dB}$. Each trial was repeated 10 times in quasi-random order and random inter-trial interval (10-20s). PPI was defined as the percent decline of the startle response: $100-[$ (startle amplitude after prepulse and pulse)/(startle amplitude after pulse only)] $\times 100$.

Spontaneous alternation in the Y-maze. Each mouse was placed at the end of one arm and allowed to move freely through the maze during an $8 \mathrm{~min}$ session. The percentage of spontaneous alternation was calculated as follows: the number of alternation (entries into three different arms consecutively) divided by the total possible alternations (ie, the number of arm entries -2$) \times 100$.

Sociability and preference for social novelty test. The social test apparatus consists of a rectangular, threechambered box illuminated by LEDs (O'Hara). A subject mouse was first placed in the middle chamber and habituated to the entire test box for $10 \mathrm{~min}$. After habituation, the subject mouse was removed from the apparatus and an unfamiliar male mouse (stranger 1) that had no prior contact with the subject mouse was placed in one of the side chambers. The location of stranger 1 in the left or right side chamber was systemically alternated between trials. The stranger 1 mouse was enclosed in a small cylindrical wire cage. An identical empty cage was placed in the opposite chamber. The subject mouse was then placed in the middle chamber and was allowed to move freely for $10 \mathrm{~min}$ (sociability test). At the end of the sociability test session, the subject mouse was removed from the apparatus, and an additional novel unfamiliar mouse (stranger 2) was enclosed in the wire cage that had previously been empty. The subject mouse was placed in the middle chamber and allowed to explore the apparatus for additional $10 \mathrm{~min}$ to assess social memory (social novelty test). The mouse behavior was recorded and analyzed by Image CSI software (O'Hara).

\section{Statistics}

Data are expressed as the mean \pm SEM, and were analyzed by Student's $t$-test, Holm's method after one-way ANOVA, or two-way repeated measures ANOVA unless otherwise stated. The log-rank test (Figure 1a and b), Dunnett's post-hoc t-test (Figure 2d), Mann-Whitney U-test (Figure 2e left), Welch's unpaired $t$-test (Figure 2e right), Bonferroni post-hoc test, or Shaffer's post-hoc test (Figure $4 \mathrm{a}-\mathrm{c}$ ) were also used. $P<0.05$ were accepted as statistically significant.

\section{RESULTS}

GAD67 and GABA Levels Were Reduced in Mice Lacking GAD67 Primarily in PV-positive GABAergic Neurons

First, we confirmed the cell types targeted for Cre activity in the $\mathrm{PV}$-Cre mouse by using a reporter mouse. As previously reported, Cre expression was detected primarily in PV-positive GABAergic neurons but also in certain other subtypes of GABAergic and pyramidal neurons (Tanahira et al, 2009). Because we focused on GABAergic neurons, we crossed the PV-Cre mouse with a VGAT-floxed STOP-tdTomato transgenic mouse. We observed that $95 \%$ of the PVimmunoreactive cells were positive for tdTomato in $\mathrm{PV}$-Cre; VGAT-floxed STOP-tdTomato mice (data not shown). Approximately $70 \%$ of tdTomato-positive cells were positive for PV (Supplementary Figure S1 and Supplementary Table S1). In addition, tdTomato-positive but PV-negative cells were, at least in part, SST- or calretinin-positive GABAergic neurons (Supplementary Figure S1 and Supplementary Table S1). Thus, Cre activity in the PV-Cre mouse was detected in a subset of GABAergic neurons, primarily in PV neurons, which is consistent with a previous study (Tanahira et al, 2009).

Next, to test whether GAD67 deficiency in a subset of GABAergic neurons, primarily in PV neurons, leads to schizophrenia-like phenotypes, we generated $P V$-Cre; GAD67 flox/flox and PV-Cre; GAD67 flox/+ mice (Supplementary Figure S2a and b) by crossing GAD67-floxed mice (Obata et al, 2008) with PV-Cre mice (Tanahira et al, 2009). Because PV is expressed in the ovary and testis (Kägi et al, 1987; Pohl et al, 1995), it is possible that undesired Cremediated recombination occurs in germ line (Kobayashi and Hensch, 2013). We observed GAD67-null mutant mice (ie, GAD6 flox/null $^{\text {and } P V-C r e ; ~ G A D 67 ~} 7^{\text {flox/null }}$ ) at a frequency of $<5 \%$. We excluded these GAD67-null mutants from further analysis (Supplementary Figure S2c). Both homozygous PV-Cre; GAD67 flox/flox and heterozygous PV-Cre; GAD67 flox/+ mice showed no gross abnormalities in their cytoarchitectures of the brain (data not shown). The survival rate of heterozygous $P V$-Cre; GAD6 flox/+ $^{\text {mice was compar- }}$ able to the control GAD67 flox/+ mice (Con, $n=116$; Het, $n=70$; Figure 1a). However, the survival rate of homozygous PV-Cre; GAD67 flox/flox mice was lower than the control GAD67 flox/flox mice (Con, $n=86$; Hom, $n=49$; log-rank test, $P<0.005$; Figure 1b) because certain homozygous $P V$-Cre; GAD67flox/flox mice developed epileptic seizures with a significantly higher risk of seizure-related sudden death. Approximately $20 \%$ of these mice died by 2 months of age.

We quantified the protein amounts of two isoforms of glutamate decarboxylase (ie, GAD67 and GAD65) in the cerebral cortex through western blot analyses (Figure 1c). 
GAD67 protein level was significantly reduced in $P V$-Cre; GAD67 flox/flox mice $(\mathrm{F}(2,6)=6.43, P<0.05$; one-way ANOVA followed by Holm's method, $P<0.05$; Figure 1d left). GAD67 protein level in $P V$-Cre; GAD6 $7^{\text {flox/+ }}$ mice was also reduced but not significantly (Figure 1d left). In contrast, GAD65 protein level in PV-Cre; GAD67 flox/flox mice was significantly increased compared with the control mice and $P V$-Cre; GAD $67^{f l o x /+}$ mice $(\mathrm{F}(2,6)=10.64, P<0.05$; one-way ANOVA followed by Holm's method, $P<0.05$ Con $v s$ Hom, $P<0.05$ Het $v s$ Hom $P<0.05$; Figure $1 \mathrm{~d}$ right). It should be a

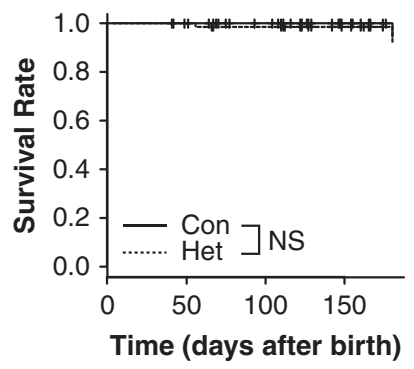

d

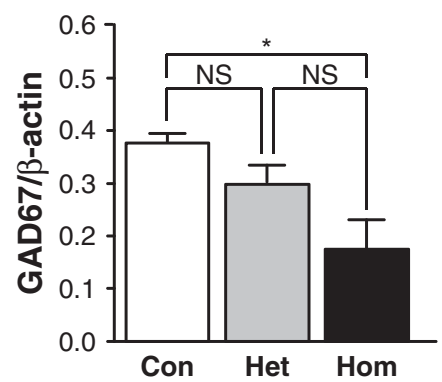

e
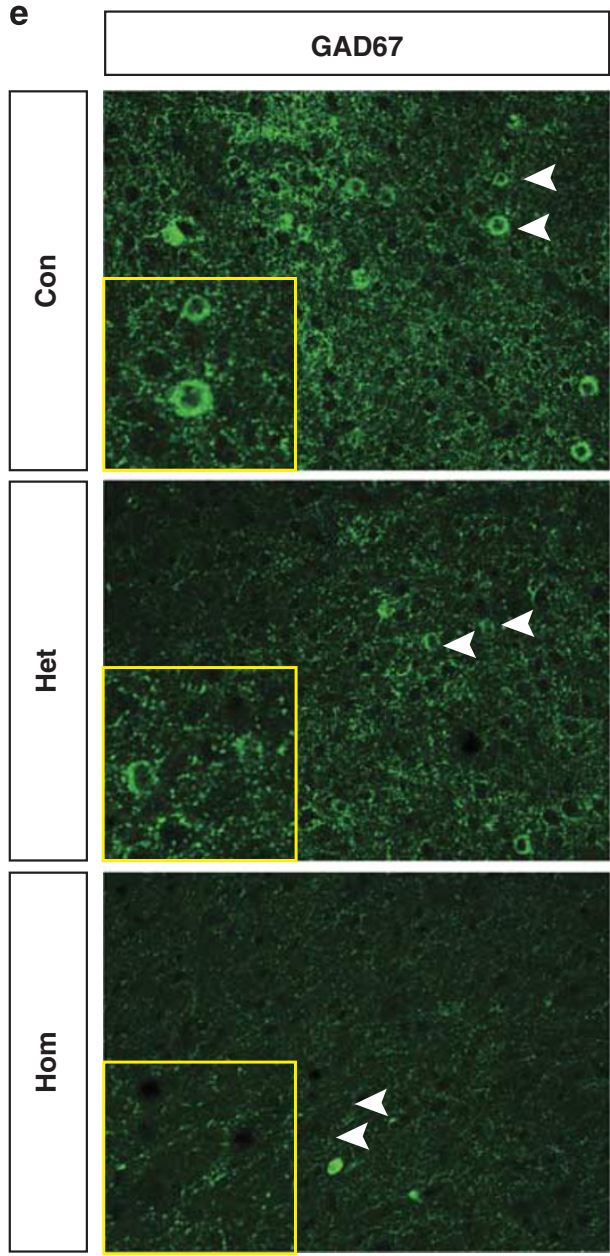
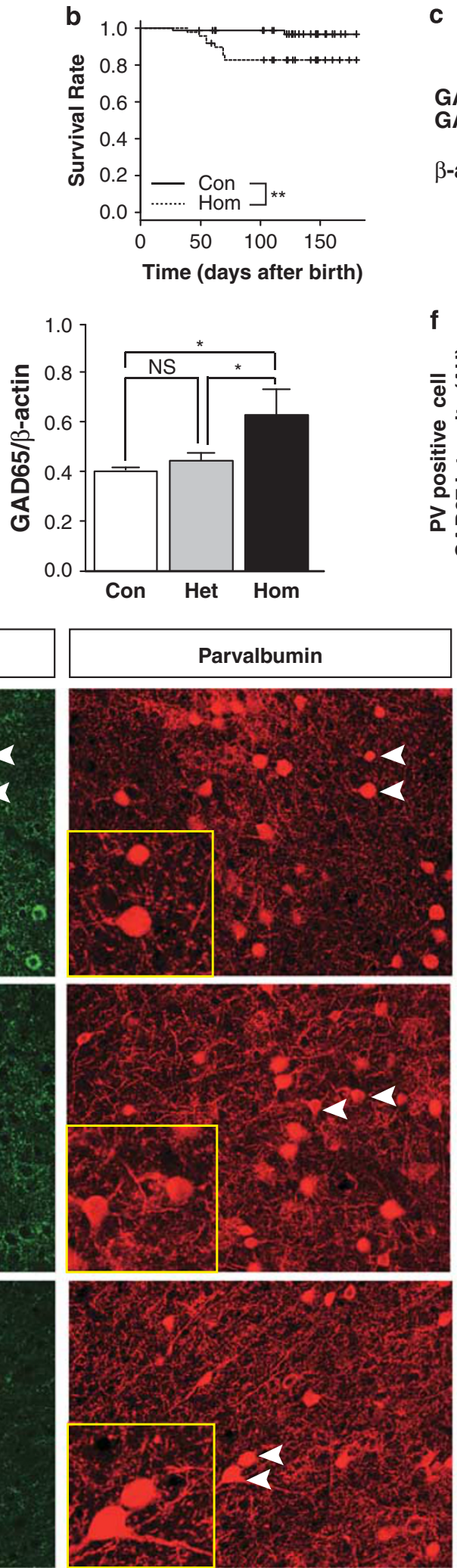
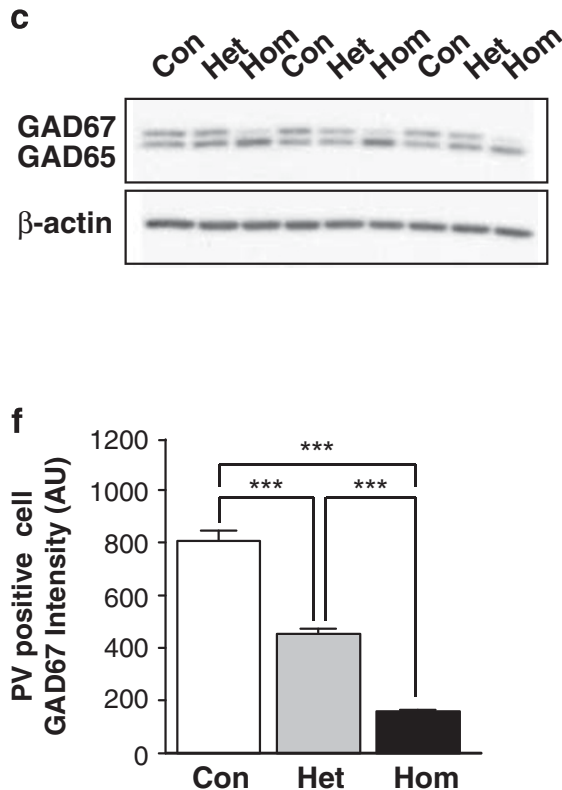
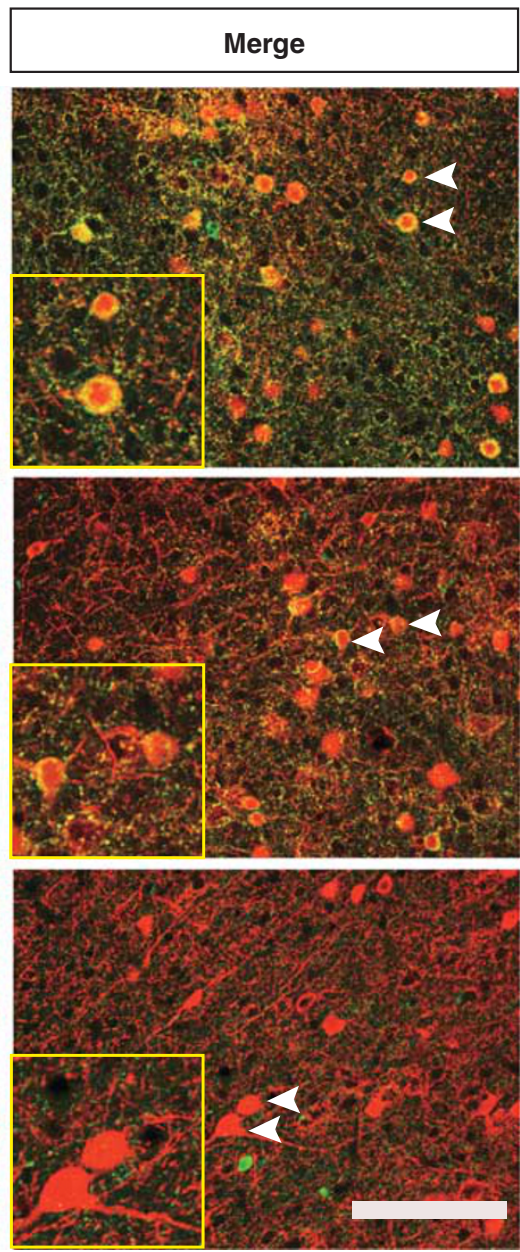
noted that the amounts of GAD67 and GAD65 in wild-type, GAD67 flox/+ , and GAD67 flox/flox mice were not significantly different (Supplementary Figure S3), which suggests that the altered GAD67 and GAD65 protein levels in PV-Cre; GAD67flox/flox mice can be attributed to Cre-mediated deletion of the GAD67 gene.

We further confirmed PV-Cre-mediated deletion of GAD67 through double immunohistochemistry for GAD67, GABA, and PV in the soma of PV-positive neurons. GAD67 immunoreactivity in the frontal cortex $(\mathrm{F}(2,106)=168.3$, $P<0.0001$; one-way ANOVA followed by Holm's method, $P<0.0001$ Con $v s$ Het, $P<0.0001$ Con $v s$ Hom; Figure 1e and f) and the hippocampal CA1 region (data not shown) was reduced in the mutant mice, reflecting the gene dosage, to nearly undetectable levels in PV-Cre; GAD6 $7^{f l o x / f l o x}$ mice. To evaluate the functional effects of the GAD67 reduction, we next examined GABA immunoreactivity (Figure 2). GABA immunoreactivity was significantly reduced in the mutant mice $(F(2,1829)=273.28, P<0.0001$; one-way ANOVA followed by Tukey's method, $P<0.0001$ Con $v s$ Het, $P<0.0001$ Con $v s$ Hom; Figure $2 \mathrm{~b}$ upper). Surprisingly, however, PV immunoreactivity was significantly increased in PV-Cre; GAD67 flox/flox mice but not in PV-Cre; GAD67 flox/+ mice $(\mathrm{F}(2,1829)=68.32, P<0.0001$; one-way ANOVA followed by Tukey's method, $P<0.0001$ Con $v s$ Hom; Figure $2 \mathrm{~b}$ bottom). Taken together, the GAD67 and GABA immunoreactivities in PV neurons of the mutant mice were reduced in a gene dose-dependent manner, whereas the GAD65 and PV immunoreactivities were increased in PV-Cre; GAD67 floxflox mice. To further evaluate the impact of GAD67 decrease in PV neurons on PV neuron dysfunction, we quantified the proportion of PV cell enwrapped with PNNs, specialized structures of the neural extracellular matrix (Kosaka and Heizmann, 1989; Figure 2c-e). The density of PNN-positive cells in PV-Cre; GAD6 flox/flox mice was significantly increased, compared with the control mice (F $(2,32)=6.08, P<0.01$; one-way ANOVA followed by Dunnett's $t$ test, $P<0.05$; Figure $2 \mathrm{~d}$ ). Therefore, these results suggest that homozygous GAD67 deletion in PV neurons leads to substantial increases in PV and GAD65 immunoreactivity and marked increase in PNNs as well as attenuated GABA levels and increases the risk of sudden, unexpected death due to epilepsy. However, because GAD67 expression in schizophrenia patients is not completely lost but is moderately decreased in PV neurons, and the primary aim of this study was to mimic the pathological changes of schizophrenia as far as possible (Guidotti et al, 2000; Todtenkopf and Benes, 1998; Woo et al, 1997; Zhang and Reynolds, 2002), we used heterozygous PV-Cre; GAD67 flox/+ mice for further experiments. We found that the number of PVpositive cells $(P<0.05$; Figure $2 \mathrm{e}$ left $)$ and the number of $\mathrm{PV}$ cells with PNNs $(t(15.15)=2.156, P<0.05$; Figure 2e right) in PV-Cre; GAD67 flox/+ mice were significantly decreased, compared with the control mice, consistent with the postmortem studies of subjects with schizophrenia (Mauney et al, 2013; Todtenkopf and Benes, 1998; Zhang and Reynolds, 2002).

\section{Synaptic Dysfunction in PV-Cre; GAD6 $7^{\text {flox/+ }}$ Mice}

We investigated synaptic function using whole-cell patchclamp recordings in the CA1 region of the hippocampus, which displays progressive functional, structural, and neurochemical alterations in imaging and postmortem brain studies of patients with schizophrenia, as well as the neocortex (Todtenkopf and Benes, 1998; Zhang and Reynolds, 2002). To this end, synaptic responses were evoked by a bipolar stimulating electrode placed in the stratum radiatum of acute hippocampal slices. We first evaluated the effects of GAD67 deficiency in PV neurons on GABAergic, inhibitory synaptic transmission to pyramidal neurons. The inputoutput relationship of $\mathrm{GABA}_{\mathrm{A}}$-IPSCs was smaller in heterozygous $P V$-Cre; GAD6 $f^{f l o x /+}$ mice (two-way ANOVA, $\mathrm{F}(1,120)=13.88, P<0.0005$ for genotype; Figure $3 \mathrm{a}$ and $\mathrm{b})$, which indicates that decreased inhibitory synaptic strength in PV-Cre; GAD67 flox/+ mice is attributable to decreased GAD67 expression in the PV neurons of $P V-C r e ; G A D 67^{f l o x /+}$ mice. Next, we investigated excitatory synaptic transmission because GABA regulates excitatory synapse formation (BenAri et al, 2004). The input-output relationship of AMPAEPSCs (Figure $3 c$ and $d$ ) and the ratio of NMDA to AMPA EPSC amplitude (Figure 3e and f) were similar in both groups, suggesting that basal excitatory synaptic transmission remains intact in PV-Cre; GAD $7^{f l o x /+}$ mice. Interestingly, however, the current-voltage $(I-V)$ curve of NMDA-EPSCs in $P V$-Cre; GAD67flox/+ mice was lower than control mice (two-way ANOVA, $\mathrm{F}(1,15)=11.52, P<0.005$ for genotype; Figure $3 \mathrm{~g}$ and $h$ ), and the membrane potential at which the NMDA receptor channel exhibited $50 \%$ of the maximal conductance $\left(V_{50}\right)$ in conductance-voltage plots was higher (Supplementary Figure S4). The rise time and the fast $\left(\tau_{\mathrm{f}}\right)$ and slow $\left(\tau_{\mathrm{s}}\right)$ decay time constant of the NMDA-EPSCs (measured at $+40 \mathrm{mV}$ ) were similar between the genotypes. To further examine synaptic dysfunction, we counted dendritic spines on biocytin-filled pyramidal neurons. We observed an increased

\footnotetext{
Figure I Mortality and GAD67 reduction in the cerebral cortex of heterozygous PV-Cre; GAD67flox/+ and homozygous PV-Cre; GAD67flox/flox mice. (a and b) The survival rate of heterozygous PV-Cre; GAD67flox/+ mice was comparable to the control mice, but the survival rate of homozygous PV-Cre; GAD67flox/flox mice was reduced. (a) Survival curves of GAD67 flox/+ (Con, $n=116$ ) and PV-Cre; GAD67 flox/+ (Het, $n=70$ ) mice (log-rank test, $P=0.42$ ). (b) Survival curves of GAD67 flox/flox (Con, $n=86$ ) and PV-Cre; GAD67 flox/flox (Hom, $n=49$ ) mice (log-rank test, $P<0.005$ ). $* * P<0.01$. (c and d) Decreased GAD67 but increased GAD65 protein levels in homozygous PV-Cre; GAD67 flox/flox mice. (c) Western blot analysis of the cerebral cortex of control GAD67 flox/+ , heterozygous PV-Cre; GAD67 $7^{\text {flox/++}}$, and homozygous PV-Cre; GAD67flox/flox mice using anti-GAD65/67 antibody with $\beta$-actin as an internal control. (d) Densitometric analysis of the expression levels of GAD67 (left) and GAD65 (right). To evaluate the protein levels of GAD65 and GAD67, the intensities of their bands in c were divided by their corresponding control ( $\beta$-actin). The data are presented as the mean \pm SEM. P-values were calculated using one-way repeated measures ANOVA followed by Holm's method. ${ }^{*} P<0.05$. (e and $f$ ) Reduction of GAD67 immunoreactivity in PV-positive neurons of the frontal cortex. Controls (Con); heterozygous PV-Cre; GAD67 flox/+ (Het); homozygous PV-Cre; GAD67flox/flox mice (Hom). The results in e were quantified in f. $n=9$ slices from three mice for each genotype (Con, Het, and Hom). ****P<0.00I; one-way repeated measures ANOVA. Scale bar, $100 \mu$ m. ANOVA, analysis of variance; GAD67, glutamate decarboxylase 67; NS, not significant; PV, parvalbumin.
} 
spine density in $P V$-Cre; GAD67 $7^{f l o x /+}$ mice $(t(23)=2.562$, $P<0.05$; Figure 3i and j), compared with control mice. These data indicate that not only inhibitory synaptic function but also excitatory synaptic function are impaired in $\mathrm{PV}$-Cre;
GAD67 flox/+ mice, which suggests that heterozygous GAD67 deletion in a subset of GABAergic neurons, mainly in PV neurons, is sufficient to cause an imbalance of excitation and inhibition in the hippocampus. a
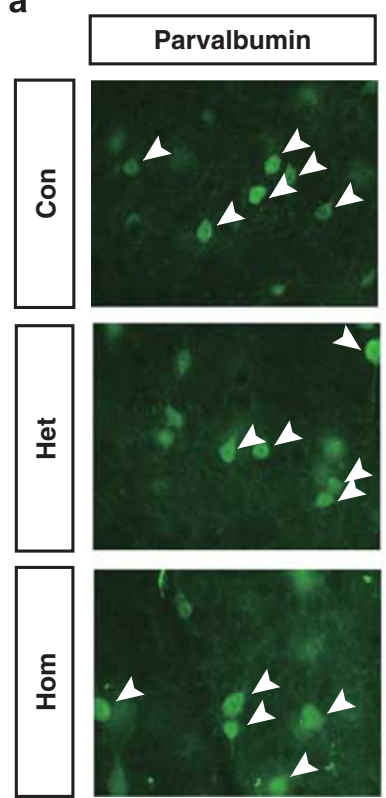
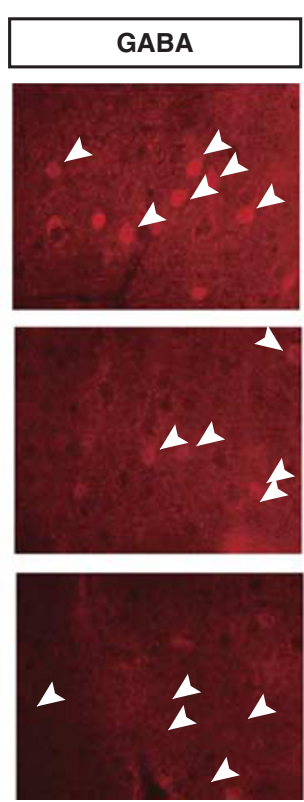
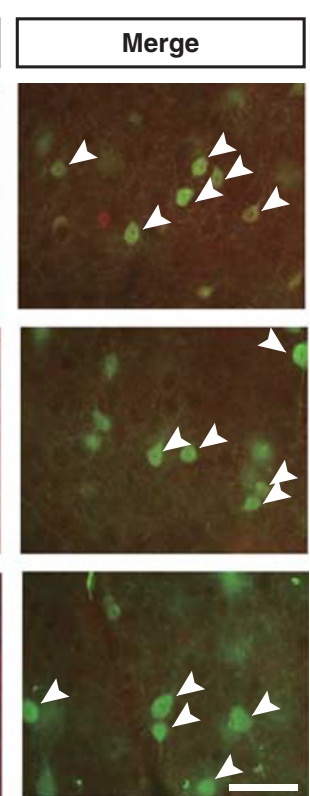
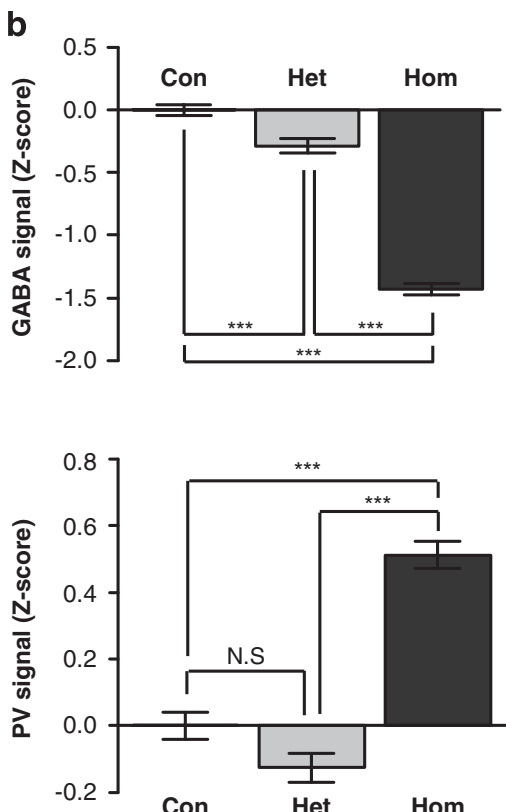

C
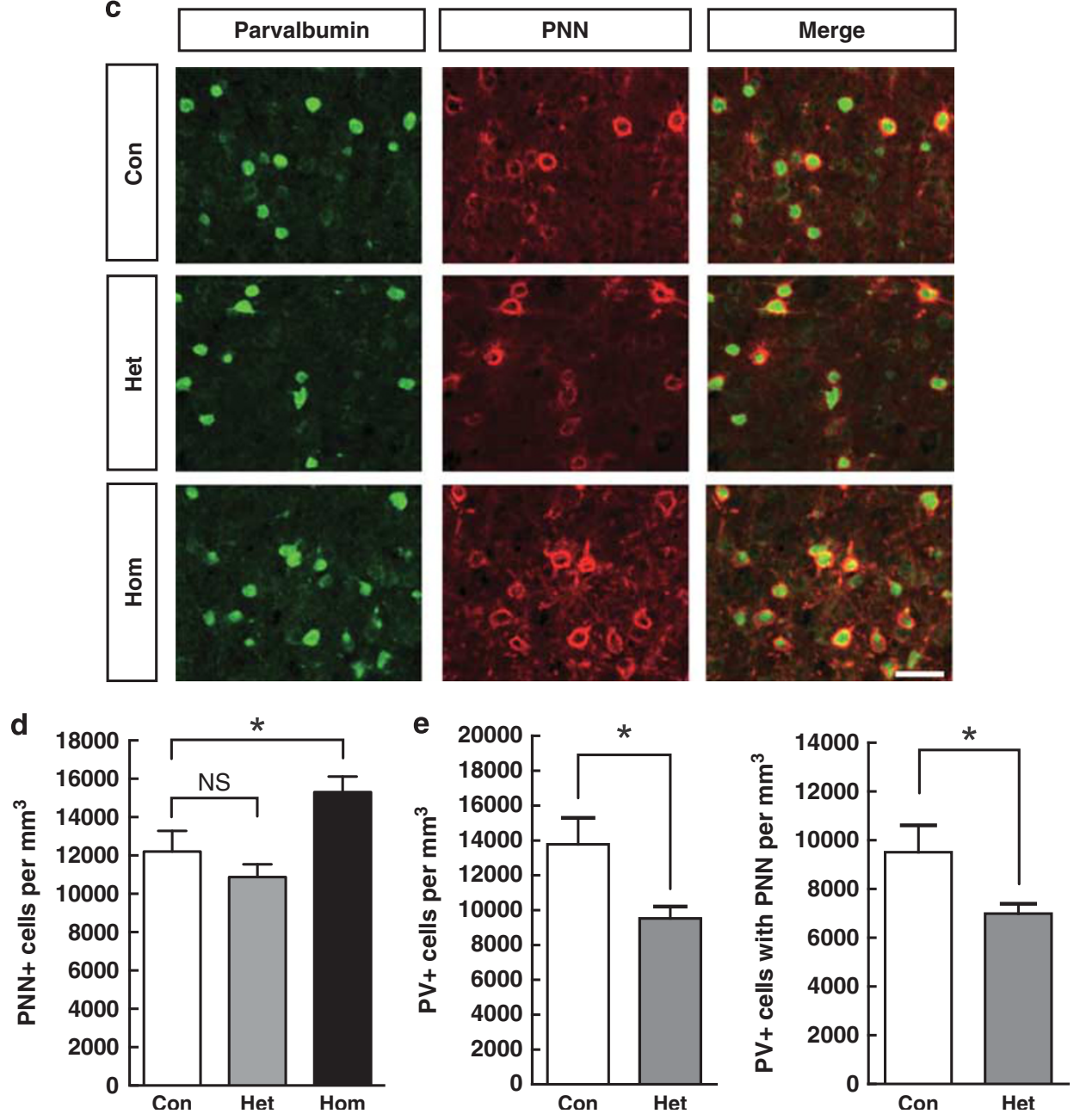


\section{Schizophrenia-Like Behavioral Features of $\mathrm{PV}$-Cre; GAD6 ${ }^{\text {flox } /+}$ Mice}

To determine whether the neurochemical and physiological disturbances in PV-Cre; GAD67 flox/+ mice produce behavioral impairments, we performed behavioral tests to assess schizophrenia-like traits. PV-Cre; GAD $67^{f l o x /+}$ mice appeared healthy and showed no obvious differences in neurological and physical characteristics, compared with the control mice (data not shown). We first tested the mice for global behavioral changes and detected no changes in anxietyrelated behaviors and motor coordination/motor learning in PV-Cre; GAD67flox/+ mice with a series of tests (light-dark transition test, elevated plus maze, Porsolt forced swim test, and rotarod test (Supplementary Figures 5)).

Hyperlocomotor activity has been correlated with the positive symptoms of schizophrenia (Lahti et al, 1995). In addition, treatment with noncompetitive NMDA receptor antagonists including ketamine, phencyclidine, and MK-801 causes schizophrenia-like psychosis in humans (BubeníkováValesová et al, 2008). Therefore, we exposed control mice and PV-Cre; GAD67 flox/+ mice to an open field for $30 \mathrm{~min}$ and then administered the psychostimulant MK-801 followed by continued exposure to the open field for $90 \mathrm{~min}$. $P V-C r e ; G A D 67^{f l o x /+}$ mice showed normal spontaneous locomotion compared with control GAD6 flox/+ mice (1-30 min; Figure 4a). The rearing number of the mutant mice tended to be slightly higher than controls, but the difference was not significant (Figure $4 \mathrm{~b}$ ). The total center time was not significantly different between the two genotypes (Figure 4c). These results indicating that $P V$-Cre; GAD $67^{f l o x /+}$ mice have normal anxiety levels, and their open field locomotion is not affected by anxiety. After MK-801 administration, both control and PV-Cre; GAD67 flox/+ mice showed a progressive increase in locomotor activity, and MK-801-induced hyperlocomotion was significantly enhanced in PV-Cre; GAD6 $f^{f l o x /+}$ mice $(31-120 \mathrm{~min}, \mathrm{~F}(1,14)=$ 11.07, $P<0.005$ for genotype; Figure $4 \mathrm{a})$. The rearing number and center time of PV-Cre; GAD $67^{\text {flox/+ }}$ tended to be slightly higher than controls after MK-801 administration but not to a significant degree (Figure $4 \mathrm{~b}$ and $\mathrm{c}$ ). Thus, these data suggest that $P V$-Cre; GAD67 flox/+ mice show more sensitivity to the locomotor-stimulating effects of MK-801.

PPI of the startle reflex, a measure of sensorimotor gating, is a well-characterized endophenotype in schizophrenia. PPI deficits have been repeatedly found in schizophrenia patients (Braff et al, 2001). We observed impaired PPI of the acoustic startle response at prepulse intensities of 70 and $75 \mathrm{~dB}$ in PV-Cre; GAD67 flox/+ mice $(\mathrm{F}(1,75)=21.02, P<0.005$ for genotype effect; Two-way repeated measures ANOVA followed by Holm's post-hoc test, $P<0.05$ for $70 \mathrm{~dB}$, $P<0.05$ for $75 \mathrm{~dB}$, and $P=0.31$ for $80 \mathrm{~dB}$; Figure $4 \mathrm{~d}$ ), whereas the amplitudes of the acoustic startle response were similar between the two genotypes (Figure 4e), thereby excluding sensorimotor defects.

Cognitive dysfunction is considered a clinical feature of schizophrenia (Piskulic et al, 2007). To examine cognitive function in $\mathrm{PV}$-Cre; GAD67 flox/+ mice, we used the Y-maze spontaneous alternation task (Paul et al, 2009). No difference was observed in the spontaneous alternation rates (Figure 4f). In addition, contextual and cued fear conditioning tests were conducted to examine learning and memory. No genotypic effects in fear conditioning or in contextual and cued fear memories were observed between the two genotypes (Supplementary Figure S9).

Social behavioral deficits including social withdrawal and isolation are frequently observed in schizophrenia patients and are key components of the negative symptoms of schizophrenia (Couture et al, 2006). To this end, a threechamber social interaction test was performed (Nadler et al, 2004). In a sociability test for social $v s$ empty preference, both the control and PV-Cre; GAD6 flox/+ $^{\text {mice spent signifi- }}$ cantly more time interacting with the stranger than with the empty cage (paired $t$-test, Con: $t(17)=4.232, P<0.001$, Het: $t(14)=4.750, P<0.0005$, respectively; Figure $4 \mathrm{~g}$ ), which indicates that the sociability of $P V$-Cre; GAD $67^{f l o x /+}$ mice remained intact. Subsequently, we examined a preference for social novelty, which relies on social memory. Control mice spent more time interacting with the novel mouse than with the familiar mouse. In contrast, $\mathrm{PV}$-Cre; GAD67 flox/+ mice did not show a preference for social novelty (paired $t$-test, Con: $t(17)=-2.365, P<0.05 ; t(14)=-0.319$, Het: $P=0.755$; Figure $4 \mathrm{~h})$. These results indicate that $P V$-Cre; GAD67flox/+ mice have normal sociability but showed an impaired social novelty preference (ie, deficits in social memory). Collectively, our results suggest that PV-Cre; GAD67 flox/+ mice exhibit schizophrenia-like behaviors.

\section{DISCUSSION}

One of the most highly replicated findings in postmortem brain studies of subjects with schizophrenia is decreased GAD67 expression in a subset of GABAergic neurons, including PV neurons. However, it has been unclear whether and how the alteration is a cause of schizophrenia-related endophenotypes or merely an effect of the disease process. We found that $P V$-Cre; GAD $67^{f l o x /+}$ mice show multiple

Figure 2 Immunohistochemical characterization of PV neuron dysfunction in the cerebral cortex of heterozygous PV-Cre; GAD67 flox/+ and homozygous PV-Cre; GAD67 $7^{\text {flox/flox }}$ mice. (a) Double immunohistochemistry for PV (green) and GABA (red) in the frontal cortex of controls (Con), heterozygous PV-Cre; GAD67 flox/+ $(\mathrm{Het}$ ), and homozygous PV-Cre; GAD67 flox/fox mice (Hom). Scale bar, $50 \mu \mathrm{m}$. (b) Signal intensities obtained from each PV-positive somata were transformed into Z-scores (normalized by the average and the SD of the data set of control GAD6 $7^{\text {flox/+ }}$ mice; upper, GABA; bottom, PV). $n=9$ slices from three mice for each genotype (Con, Het, and Hom). ${ }^{*} * P<0.0$ I, ${ }^{*} * * P<0.00 I$. The error bars indicate the mean \pm SEM one-way ANOVA followed by Holm's method. (c) Double immunohistochemistry for PV (green) and PNNs (red) in the frontal cortex of controls (Con), heterozygous PV-Cre; GAD67flox/+ (Het),

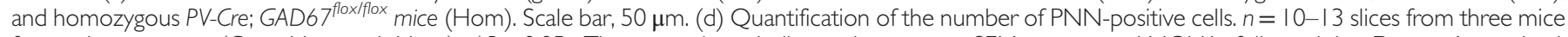
for each genotype (Con, Het, and Hom). $* P<0.05$. The error bars indicate the mean \pm SEM one-way ANOVA followed by Dunnett's method. (e) Quantification of the number of PV-positive cells (left), and PV-neurons with PNNs (right). $n=10-13$ slices from three mice for each genotype (Con, Het). *P < 0.05; left, Mann-Whitney U-test; right, Welch's unpaired t-test. ANOVA, analysis of variance; GAD67, glutamate decarboxylase 67; NS, not significant; $\mathrm{PV}$, parvalbumin. 

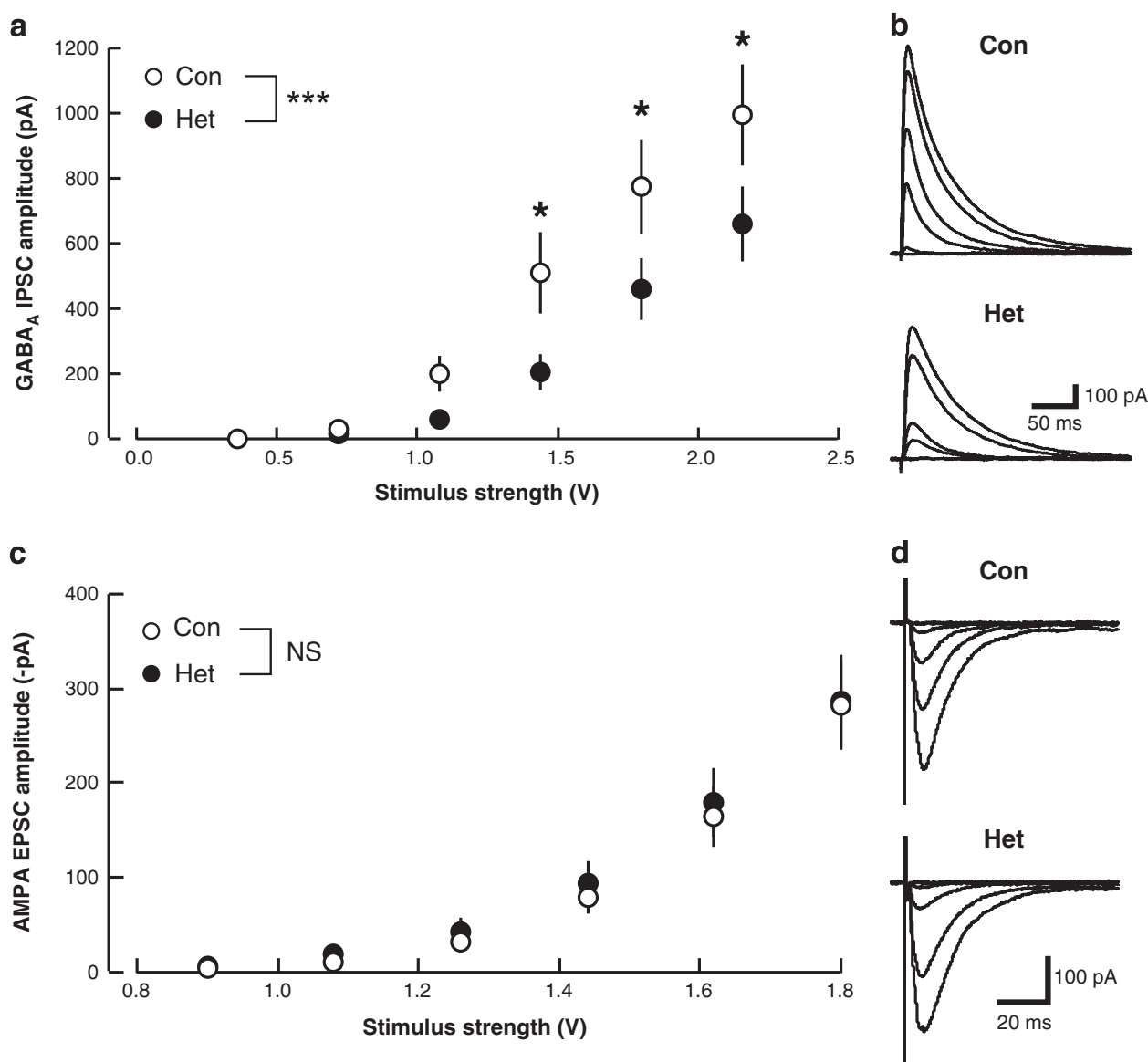

$\mathbf{f}$

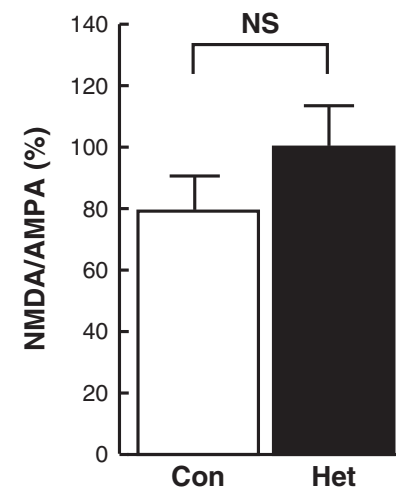

g

h

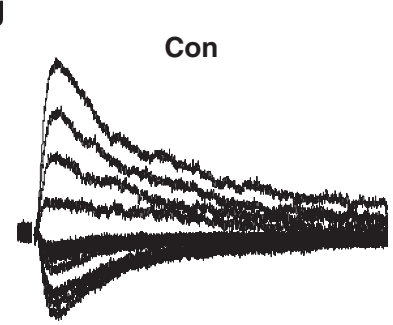

- $\left.\begin{array}{l}\text { Het } \\ \text { - }\end{array}\right]$ **
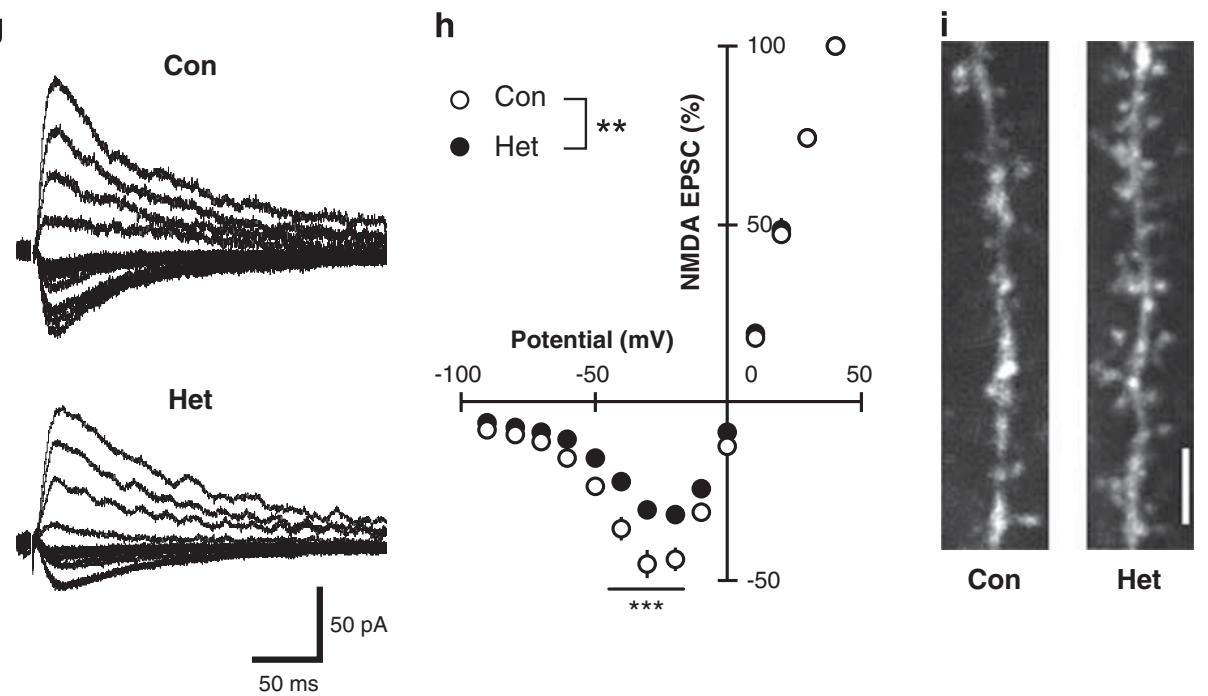
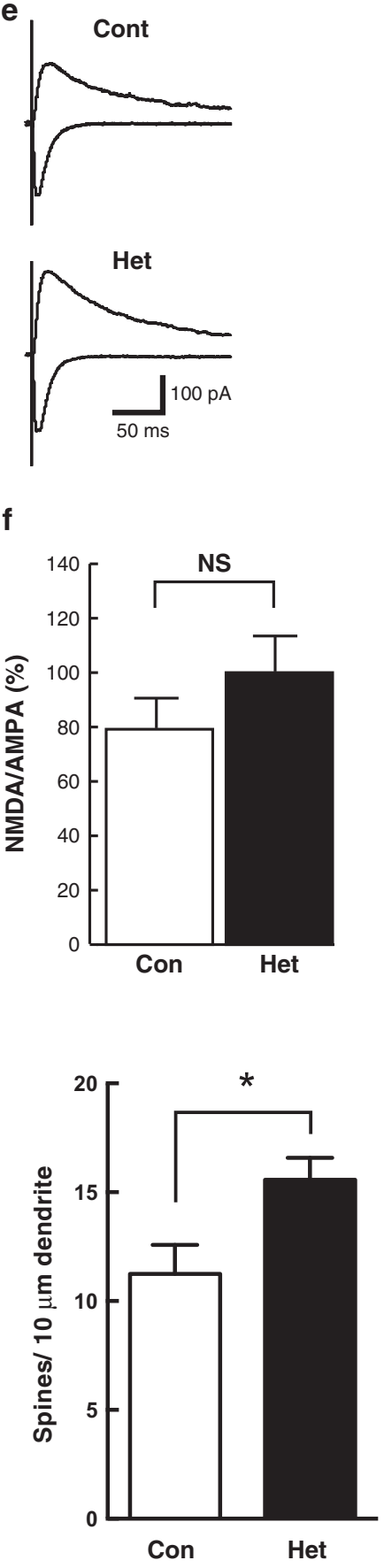

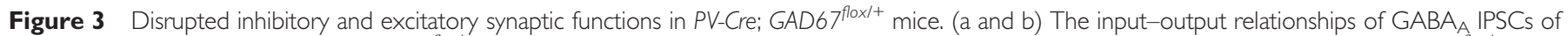
controls (Con, $n=1 I$ ) and PV-Cre; GAD67 flox/+ mice (Het, $n=1 I$ ). GABA ${ }_{A}$ receptor-mediated synaptic responses were smaller in PV-Cre; GAD67 flox/+ mice than in controls. $P=0.0003$ by two-way repeated measures ANOVA. $* P<0.05$ by Bonferroni post-hoc test. Representative traces are shown in b. (c and $d$ ) The input-output relationships of AMPA EPSCs of controls (Con, $n=17$ ) and PV-Cre; GAD67 $7^{\text {flox } /+}$ mice (Het, $n=15$ ). $P=0.74$ by two-way repeated measures ANOVA. Representative traces are shown in d. (e) AMPA receptor-mediated EPSCs (downward traces) and NMDA receptor-mediated EPSC (upward traces) were recorded at membrane potentials of -90 and $+40 \mathrm{mV}$, respectively. ( $\mathrm{f}$ ) The ratio of amplitudes of NMDA EPSCs to those of AMPA EPSCs was similar between the two genotypes $(P=0.26)$. (g) NMDA EPSCs were recorded at membrane potentials between +40 and $-90 \mathrm{mV}$. ( $\mathrm{h}$ ) The current amplitudes were normalized to the value obtained at $+40 \mathrm{mV}$ in each cell, and the values were then averaged for all cells. NMDA EPSCs in PV-Cre; GAD67flox/+ mice displayed significantly smaller synaptic currents in the I-V curve at membrane potentials between -40 and $-20 \mathrm{mV}$ in PV-Cre; GAD67 flox/+ mice (Con, $n=9$; Het, $n=8$; ** $P<0.005$ by two-way repeated measures ANOVA). ${ }^{*} * *<0.00$ I by Bonferroni post-hoc test. (i) Representative maximum intensity projection images of secondary apical dendrites of pyramidal neurons from a control and PV-Cre; GAD67 flox/+ mice. Scale bar, $3 \mu \mathrm{m}$. (j) Quantification of secondary dendrite spine density in control $(1| \pm|$ spines per $10 \mu \mathrm{m}, n=13)$ and $P V$-Cre; GAD67flox $/+(16 \pm \mid$ spines per $10 \mu \mathrm{m}, n=\mid 2)$ neurons $(P<0.05)$. ANOVA, analysis of variance; GAD67, glutamate decarboxylase 67; NS, not significant; PV, parvalbumin. 

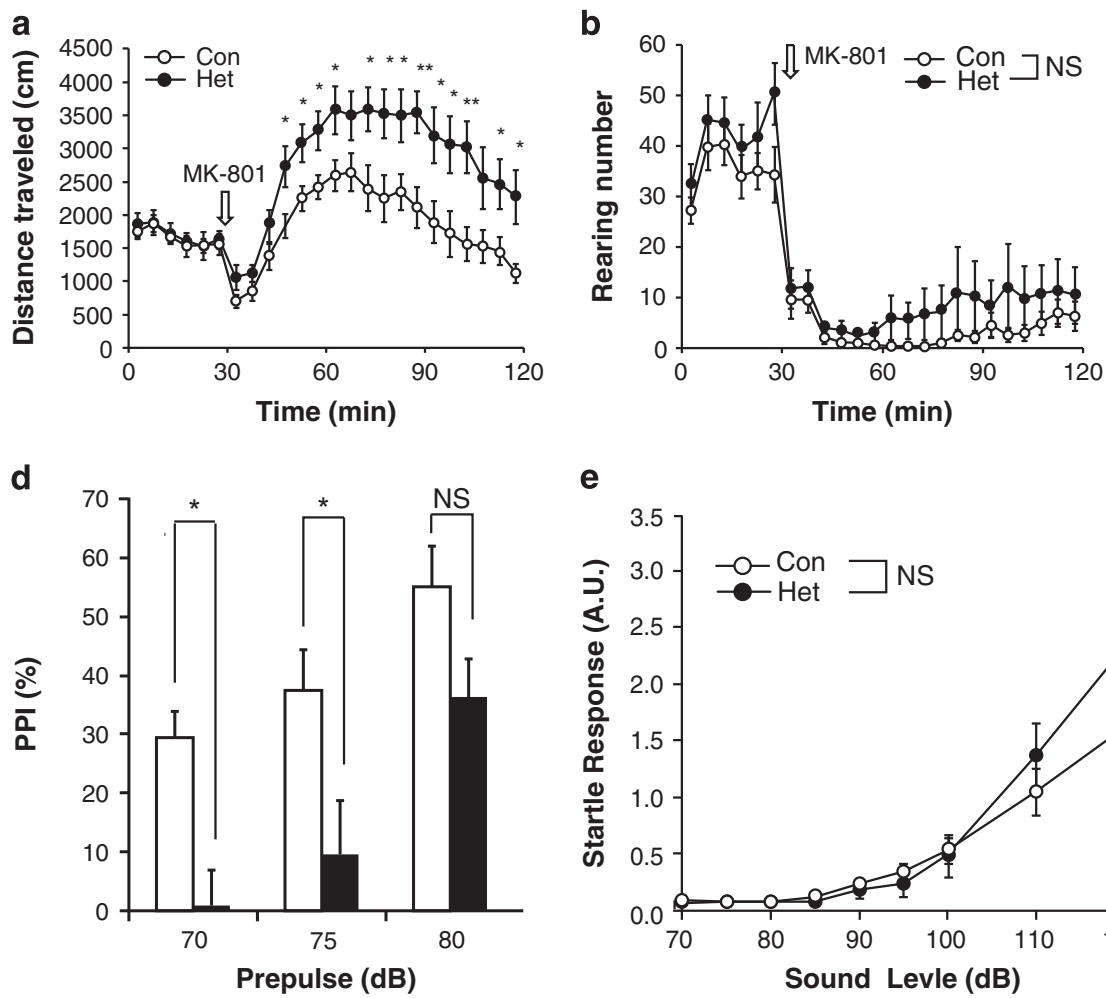

g
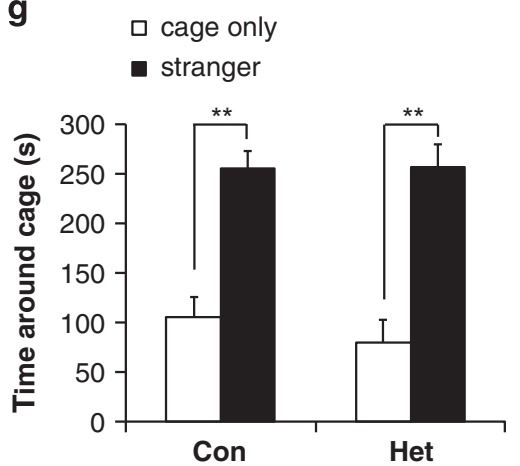

h

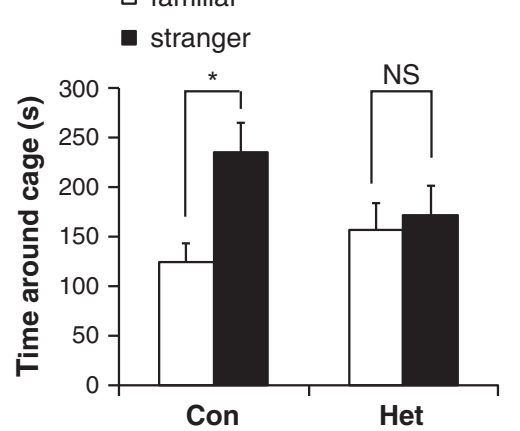

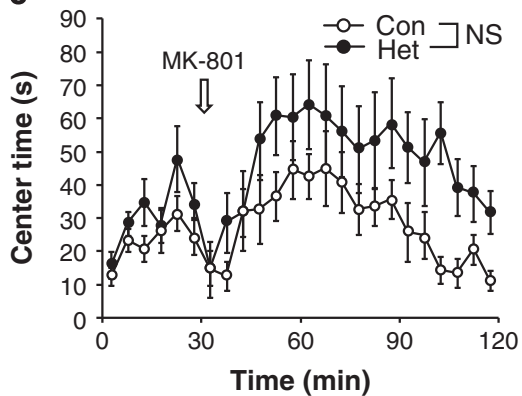

f
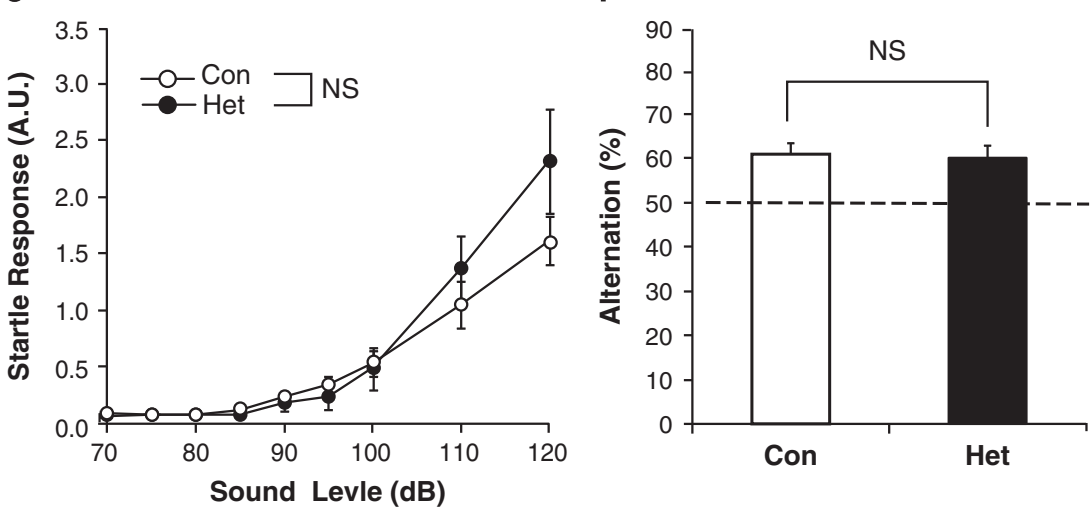

Figure 4 Schizophrenia-related behaviors in PV-Cre; GAD67 flox/t mice. (a-c) Normal spontaneous locomotion $(I-30$ min; $P=0.2 I)$ but locomotor stimulatory effect of MK-80I in an open field was significantly greater in PV-Cre; GAD67foxi+ mice compared with controls (Con, $n=\mid 0$; Het, $n=9$; $31-$ 120 min, $P<0.05$, two-way repeated measures ANOVA, $* P<0.05$, $* * P<0.0$ I by Shaffer's post-hoc test). Distance traveled (a), rearing number (b), and time spent in the center area (c). (d) Prepulse inhibition for the 70 and $75 \mathrm{~dB}$ prepulse sound levels followed by $120 \mathrm{~dB}$ startle stimulus was significantly impaired in $P V$-Cre; GAD6 $7^{f l o x /+}$ mice compared with controls $(P<0.005$, two-way repeated measures ANOVA; $P<0.05$ for $70 \mathrm{~dB} ; P<0.05$ for $75 \mathrm{~dB}$, and $P=0.3 \mathrm{I}$ for $80 \mathrm{~dB}$ by Holm's post-hoc test). (e) Acoustic startle responses were not different between genotypes $(P=0.47$. Two-way repeated measures ANOVA). (f) Y-maze spontaneous alternation task. There was no significant difference between the two genotypes (Con, $n=\mid 8 ; H$ et, $n=\mid 5 ; P=0.55)$. (g) In the sociability test, PV-Cre; GAD6 $7^{\text {floxl+ }}$ mice spent time interacting with the novel targets comparable to controls (paired t-test, Con; $P<0.0005, H$ et; $P<0.00$ I, respectively). (h) In the social novelty test, $P V$-Cre; GAD67 flox/f mice spent significantly less time interacting with the novel targets than controls (paired $t$-test, Con, $P<0.005$; Het, $P=0.75$. Con, $n=18$; Het, $n=15$. ANOVA, analysis of variance; GAD67, glutamate decarboxylase 67; NS, not significant; $\mathrm{PV}$, parvalbumin.

behavioral alterations related to schizophrenia. Furthermore, we showed that the number of PV neurons in the cerebral cortex was decreased, inhibitory transmission was reduced, and the properties of NMDA receptor-mediated synaptic responses in the hippocampus were altered in PV-Cre; GAD $67^{f l o x /+}$ mice. These results suggest that haploinsufficiency of the GAD67 gene in a subset of GABAergic neurons, including PV neurons, gives rise to schizophrenia-related endophenotypes, thus supporting the hypothesis that GAD67 deficiency in PV neurons is involved in disease pathogenesis.
We note that most schizophrenia cases appear to be a polygenic rather than a single gene disorder with several risk genes of small effect (Insel, 2010). However, several genetically modified mouse models for genes relevant to schizophrenia and pharmacological rodent models for schizophrenia have suggested that they commonly impair GAD67 expression, especially in PV-positive subtypes: cortical interneuron-specific GluN1-knockout mice exhibit GAD67 reduction in cortical GABAergic neurons including PV-positive subtypes (Belforte et al, 2010); ketamine 
administration, based on the hypoglutamatergic hypothesis, decreases GAD67 and PV expression in the cerebral cortex (Behrens et al, 2007); methylazoxymethanol acetate administration on gestational day 15 , based on the developmental disruption hypothesis, reduces the expression of PVcontaining interneurons in the cerebral cortex (Lodge et al, 2009); repeated amphetamine administration following longterm withdrawal periods, based on the endogenous dopamine sensitization hypothesis, induces a downregulation of GAD67 immunoreactivities in the hippocampus, prefrontal cortex, thalamus, and amygdala (Peleg-Raibstein et al, 2008). Our results suggest that in these model rodents, GAD67 deficiency contributes to the development of schizophrenialike phenotypes and is a common pathway in schizophrenia pathogenesis. In addition, there are a number of rodent models of schizophrenia showing PV neuron deficiency: functional DISC1 deficits decrease PV-positive neurons (Hikida et al, 2007); PV neuron-specific ErbB4-knockout mice exhibit schizophrenia-relevant phenotypes (Wen et al, 2010); prenatal infection with the viral mimic polyriboinosinic-polyribocytidylic acid, a model based on epidemiological studies, reduces the density of PV-positive neurons (Ducharme et al, 2012). Based on these reports and together with our data, we speculate that GAD67 deficiency in PVpositive interneurons in these rodent models relates to the development of their schizophrenia-relevant phenotypes, albeit with heterogeneous mechanisms for the dysfunction of PV-positive neurons.

How could GAD67 deficiency in a subset of GABAergic neurons induce certain schizophrenia-like phenotypes in mice? PV-Cre; GAD67 flox/+ mice show reduced GAD67 expression and decreased $\mathrm{GABA}_{\mathrm{A}}$ receptor-mediated inhibitory synaptic transmission without affecting AMPA receptor-mediated excitatory synaptic transmission. $P V$ Cre; GAD $67^{f l o x /+}$ mice also have an altered $I-V$ relationship of NMDA EPSCs and exhibit increased number of dendritic spine density in the pyramidal neurons of the hippocampal CA1 region. The properties of the NMDA receptors in $P V$ Cre; GAD67 flox/+ mice are similar to those in the neonatal hippocampal CA1 region (Kirson et al, 1999). Because GABA regulates excitatory synapse formation (Ben-Ari et al, 2004), these results imply that reduced GABA expression levels in PV-Cre; GAD67 flox/+ mice disturb developmental pruning (Huttenlocher and Dabholkar, 1997) and the maturation of excitatory synaptic functions, even though dendritic spine density on prefrontal cortical pyramidal neurons in subjects with schizophrenia are decreased (Glantz and Lewis, 2000). One of the characteristic properties of NMDA receptors is the blockade of the receptor channel by extracellular $\mathrm{Mg}^{2+}$ block at negative membrane potentials and it has a critical role in activity-dependent modifications of excitatory synapses that are observed during long-term potentiation and synapse formation (Hunt and Castillo, 2012). The timing of $\mathrm{Mg}^{2+}$ unblock is critical in determining the contribution of NMDA receptors to spike generation (Schiller and Schiller, 2001). The low voltage dependence of NMDA receptors in mutant mice would affect the time course of $\mathrm{Mg}^{2+}$ unblock to detect coincident pre and postsynaptic activity and may impede excitatory synaptic maturation and plasticity in the adult hippocampus. Taken together, the balance between excitation and inhibition in CA1 pyramidal neurons is shifted toward excitation in the mutant mice. In fact, enhanced hippocampal activity has been reported in animal models and schizophrenia patients (Lodge et al, 2009; Schobel et al, 2009) and correlates with enhanced dopamine neuron activity and positive symptoms (Blaha et al, 1997; Legault and Wise, 1999). The PV-Cre; GAD67flox/+ mice exhibited enhanced MK-801-induced hyperlocomotion in the open field test. Because hyperlocomotor activity is commonly considered a behavior of increased dopaminergic tone (Laruelle and Abi-Dargham, 1999), the motor stimulatory effects of MK-801 in PV-Cre; GAD f $^{f l o x /+}$ mice might be associated with subcortical dopamine hyperfunction. To clarify this issue, further examination would be required.

Homozygous PV-Cre; GAD67floxfflox mice showed increased GAD65 and PV expression and increased number of PNN-positive cells, and some of them exhibited epileptic seizures. These results are inconsistent with the following results of postmortem brain studies of patients with schizophrenia (Beasley and Reynolds, 1997; Guidotti et al, 2000; Hashimoto et al, 2008; Mauney et al, 2013; Todtenkopf and Benes, 1998; Woo et al, 1997; Zhang and Reynolds, 2002): (1) GAD65 mRNA and protein expression levels are unaffected or downregulated in the cerebral cortex of schizophrenic patients; (2) mRNA levels of PV in the cerebral cortex are lower in schizophrenic patients than control subjects; (3) lower PV mRNA levels have been found in a number of animal models for schizophrenia; and (4) the densities of PNNs are decreased in the prefrontal cortex in schizophrenia compared with normal control subjects. Because the regulation of PV-synaptic innervations during the maturation of inhibitory circuits is dependent on GAD67-mediated GABA synthesis (Chattopadhyaya et al, 2007), the dysfunction of PV inhibitory circuits cause a further excitation of pyramidal neurons. This effect could contribute to epileptic seizure generation and induce compensatory responses in homozygous PV-Cre; GAD67floxfflox mice. In fact, such seizure activity has been known to involve compensatory changes in gene expression including the upregulation of GAD65 and $\mathrm{PV}$ expression in the hippocampus (Esclapez and Houser, 1999; Hwang et al, 2007). Therefore, since GAD67 mRNA and protein levels are moderately reduced, not completely lost, in schizophrenia relative to matched control subjects (Guidotti et al, 2000; Hashimoto et al, 2003; Torrey et al, 2005; Volk et al, 2000), heterozygous PV-Cre; GAD67flox/+ mice are a new, potential rodent model of schizophrenia that will be useful for further understanding schizophrenia pathogenesis.

In conclusion, we describe a new association between GAD67 deficiency in a mouse model and the results from postmortem brain studies of schizophrenia patients. Haploinsufficiency of the GAD67 gene in a subset of GABAergic neurons, primarily in PV neurons, gives rise to schizophrenia-related endophenotypes and alterations in both excitatory and inhibitory synaptic functions. These findings are consistent, in several respects, with results of other reports (Brown et al, 2015; Lazarus et al, 2013). Therefore, our findings support the hypothesis that GAD67 deficiency is a possible common pathway that induces the pathogenesis of schizophrenia and provide a novel link between GAD67 deficiency and impaired NMDA-mediated synaptic transmission. 


\section{FUNDING AND DISCLOSURE}

The authors declare no conflict of interest.

\section{ACKNOWLEDGMENTS}

We thank Drs Yasuhiko Saito and Hiroki Yasuda for their helpful comments on the manuscript and the members of our laboratory for their technical assistance and critical comments. We also thank Dr Minato Nakazawa for statistical advice and the staff at the Institute of Experimental Animal Research, the Gunma University Graduate School of Medicine for technical help. We are grateful to Dr Kunihiko Obata for his encouragement. This work was supported by Grants-in-Aid for Scientific Research from the Ministry of Education, Science, Sports, Culture, and Technology of Japan (YY), a grant from the Co-operative Study Program of National Institute for Physiological Sciences, Japan (YY), the Takeda Science Foundation (YY), the Mitsubishi Pharma Research Foundation (HM), the Naito Foundation (KF), and the Support Program of Gunma University Graduate School of Medicine for Improving Graduate School Education (KF).

\section{AUTHOR CONTRIBUTIONS}

$\mathrm{KF}, \mathrm{HM}$, and $\mathrm{YY}$ designed the research? KF and HM performed the research; TK, MM, NT, and YY contributed reagents/analytic tools; $\mathrm{CT}$ and NT generated the $P V$-Cre mice; RK generated the VGAT-floxed STOP-tdTomato mice; $\mathrm{KF}$ and HM analyzed the data; and KF, HM, and YY prepared the manuscript, which was approved by all authors.

\section{REFERENCES}

Beasley CL, Reynolds GP (1997). Parvalbumin-immunoreactive neurons are reduced in the prefrontal cortex of schizophrenics. Schizophr Res 24: 349-355.

Behrens MM, Ali SS, Dao DN, Lucero J, Shekhtman G, Quick KL et al (2007). Ketamine-induced loss of phenotype of fast-spiking interneurons is mediated by NADPH-oxidase. Science 318: 1645-1647.

Belforte JE, Zsiros V, Sklar ER, Jiang Z, Yu G, Li Y et al (2010). Postnatal NMDA receptor ablation in corticolimbic interneurons confers schizophrenia-like phenotypes. Nat Neurosci 13: 76-83.

Ben-Ari Y, Khalilov I, Represa A, Gozlan H (2004). Interneurons set the tune of developing networks. Trends Neurosci 27: 422-427.

Blaha CD, Yang CR, Floresco SB, Barr AM, Phillips AG (1997). Stimulation of the ventral subiculum of the hippocampus evokes glutamate receptor-mediated changes in dopamine efflux in the rat nucleus accumbens. Eur J Neurosci 9: 902-911.

Braff DL, Geyer MA, Swerdlow NR (2001). Human studies of prepulse inhibition of startle: normal subjects, patient groups, and pharmacological studies. Psychopharmacology (Berl) 156: 234-258.

Brown JA, Ramikie TS, Schmidt MJ, Báldi R, Garbett K, Everheart MG et al (2015). Inhibition of parvalbumin-expressing interneurons results in complex behavioral changes. Mol Psychiatry; e-pub ahead of print 27 January 2015; doi:10.1038/mp.2014.192.

Bubeníková-Valesová V, Horácek J, Vrajová M, Höschl C (2008). Models of schizophrenia in humans and animals based on inhibition of NMDA receptors. Neurosci Biobehav Rev 32: 1014-1023.

Chattopadhyaya B, Di Cristo G, Wu CZ, Knott G, Kuhlman S, Fu Y et al (2007). GAD67-mediated GABA synthesis and signaling regulate inhibitory synaptic innervation in the visual cortex. Neuron 54: 889-903.
Couture SM, Penn DL, Roberts DL (2006). The functional significance of social cognition in schizophrenia: a review. Schizophr Bull 32(Suppl 1): S44-S63.

Ducharme G, Lowe GC, Goutagny R, Williams S (2012). Early alterations in hippocampal circuitry and theta rhythm generation in a mouse model of prenatal infection: implications for schizophrenia. PLoS One 7: e29754.

Esclapez M, Houser CR (1999). Up-regulation of GAD65 and GAD67 in remaining hippocampal GABA neurons in a model of temporal lobe epilepsy. J Comp Neurol 412: 488-505.

Glantz LA, Lewis DA (2000). Decreased dendritic spine density on prefrontal cortical pyramidal neurons in schizophrenia. Arch Gen Psychiatry 57: 65-73.

Guidotti A, Auta J, Davis JM, Di-Giorgi-Gerevini V, Dwivedi Y, Grayson DR et al (2000). Decrease in reelin and glutamic acid decarboxylase67 (GAD67) expression in schizophrenia and bipolar disorder: a postmortem brain study. Arch Gen Psychiatry 57: 1061-1069.

Hashimoto T, Arion D, Unger T, Maldonado-Avilés JG, Morris HM, Volk DW et al (2008). Alterations in GABA-related transcriptome in the dorsolateral prefrontal cortex of subjects with schizophrenia. Mol Psychiatry 13: 147-161.

Hashimoto T, Volk DW, Eggan SM, Mirnics K, Pierri JN, Sun Z et al (2003). Gene expression deficits in a subclass of GABA neurons in the prefrontal cortex of subjects with schizophrenia. $J$ Neurosci 23: 6315-6326.

Hikida T, Jaaro-Peled H, Seshadri S, Oishi K, Hookway C, Kong S et al (2007). Dominant-negative DISC1 transgenic mice display schizophrenia-associated phenotypes detected by measures translatable to humans. Proc Natl Acad Sci USA 104: 14501-14506.

Hunt DL, Castillo PE (2012). Synaptic plasticity of NMDA receptors: mechanisms and functional implications. Curr Opin Neurobiol 22: 496-508.

Huttenlocher PR, Dabholkar AS (1997). Regional differences in synaptogenesis in human cerebral cortex. J Comp Neurol 387: 167-178.

Hwang I, Kim D-W, Yoo K-Y, Kang T-C, Kim Y, Kwon D et al (2007). Parvalbumin immunoreactivity and protein content alter in the hippocampus after adrenalectomy in seizure sensitive gerbils. Neurol Res 29: 441-448.

Insel TR (2010). Rethinking schizophrenia. Nature 468: 187-193.

Kägi U, Berchtold MW, Heizmann CW (1987). Ca ${ }^{2+}$-binding parvalbumin in rat testis. Characterization, localization, and expression during development. J Biol Chem 262: 7314-7320.

Kirson ED, Schirra C, Konnerth A, Yaari Y (1999). Early postnatal switch in magnesium sensitivity of NMDA receptors in rat CA1 pyramidal cells. J Physiol 521(Pt 1): 99-111.

Kobayashi Y, Hensch TK (2013). Germline recombination by conditional gene targeting with Parvalbumin-Cre lines. Front Neural Circuits 7: 168.

Kosaka T, Heizmann CW (1989). Selective staining of a population of parvalbumin-containing GABAergic neurons in the rat cerebral cortex by lectins with specific affinity for terminal $\mathrm{N}$-acetylgalactosamine. Brain Res 483: 158-163.

Lahti AC, Koffel B, LaPorte D, Tamminga CA (1995). Subanesthetic doses of ketamine stimulate psychosis in schizophrenia. Neuropsychopharmacology 13: 9-19.

Laruelle M, Abi-Dargham A (1999). Dopamine as the wind of the psychotic fire: new evidence from brain imaging studies. J Psychopharmacol 13: 358-371.

Lazarus MS, Krishnan K, Huang ZJ (2013). GAD67 deficiency in parvalbumin interneurons produces deficits in inhibitory transmission and network disinhibition in mouse prefrontal cortex. Cereb Cortex 25: 1290-1296.

Lee FHF, Zai CC, Cordes SP, Roder JC, Wong AHC (2013). Abnormal interneuron development in disrupted-in-schizophrenia1 L100P mutant mice. Mol Brain 6: 20.

Legault M, Wise RA (1999). Injections of N-methyl-D-aspartate into the ventral hippocampus increase extracellular dopamine in 
the ventral tegmental area and nucleus accumbens. Synapse 31: 241-249.

Liu WS, Pesold C, Rodriguez MA, Carboni G, Auta J, Lacor P et al (2001). Down-regulation of dendritic spine and glutamic acid decarboxylase 67 expressions in the reelin haploinsufficient heterozygous reeler mouse. Proc Natl Acad Sci USA 98: 3477-3482.

Lodge DJ, Behrens MM, Grace AA (2009). A loss of parvalbumincontaining interneurons is associated with diminished oscillatory activity in an animal model of schizophrenia. J Neurosci 29: 2344-2354.

Mauney SA, Athanas KM, Pantazopoulos H, Shaskan N, Passeri E, Berretta S et al (2013). Developmental pattern of perineuronal nets in the human prefrontal cortex and their deficit in schizophrenia. Biol Psychiatry 74: 427-435.

Miwa H, Fukaya M, Watabe AM, Watanabe M, Manabe T (2008). Functional contributions of synaptically localized NR2B subunits of the NMDA receptor to synaptic transmission and long-term potentiation in the adult mouse CNS. J Physiol 586: 2539-2550.

Nadler JJ, Moy SS, Dold G, Trang D, Simmons N, Perez A et al (2004). Automated apparatus for quantitation of social approach behaviors in mice. Genes Brain Behav 3: 303-314.

Obata K, Hirono M, Kume N, Kawaguchi Y, Itohara S, Yanagawa Y (2008). GABA and synaptic inhibition of mouse cerebellum lacking glutamate decarboxylase 67. Biochem Biophys Res Commun 370: 429-433.

Paul C-M, Magda G, Abel S (2009). Spatial memory: theoretical basis and comparative review on experimental methods in rodents. Behav Brain Res 203: 151-164.

Peleg-Raibstein D, Knuesel I, Feldon J (2008). Amphetamine sensitization in rats as an animal model of schizophrenia. Behav Brain Res 191: 190-201.

Piskulic D, Olver JS, Norman TR, Maruff P (2007). Behavioural studies of spatial working memory dysfunction in schizophrenia: a quantitative literature review. Psychiatry Res 150: 111-121.

Pohl V, Pattyn G, Berchtold M (1995). Parvalbumin expression during developmental differentiation of the rat ovary. Differentiation 59: 235-242.
Schiller J, Schiller Y (2001). NMDA receptor-mediated dendritic spikes and coincident signal amplification. Curr Opin Neurobiol 11: 343-348.

Schobel SA, Lewandowski NM, Corcoran CM, Moore H, Brown T, Malaspina D et al (2009). Differential targeting of the CA1 subfield of the hippocampal formation by schizophrenia and related psychotic disorders. Arch Gen Psychiatry 66: 938-946.

Takao K, Kobayashi K, Hagihara H, Ohira K, Shoji H, Hattori S et al (2013). Deficiency of schnurri-2, an MHC enhancer binding protein, induces mild chronic inflammation in the brain and confers molecular, neuronal, and behavioral phenotypes related to schizophrenia. Neuropsychopharmacology 38: 1409-1425.

Tanahira C, Higo S, Watanabe K, Tomioka R, Ebihara S, Kaneko T et al (2009). Parvalbumin neurons in the forebrain as revealed by parvalbumin-Cre transgenic mice. Neurosci Res 63: 213-223.

Todtenkopf MS, Benes FM (1998). Distribution of glutamate decarboxylase65 immunoreactive puncta on pyramidal and nonpyramidal neurons in hippocampus of schizophrenic brain. Synapse 29: 323-332.

Torrey EF, Barci BM, Webster MJ, Bartko JJ, Meador-Woodruff JH, Knable MB (2005). Neurochemical markers for schizophrenia, bipolar disorder, and major depression in postmortem brains. Biol Psychiatry 57: 252-260.

Volk DW, Austin MC, Pierri JN, Sampson AR, Lewis DA (2000). Decreased glutamic acid decarboxylase67 messenger RNA expression in a subset of prefrontal cortical gamma-aminobutyric acid neurons in subjects with schizophrenia. Arch Gen Psychiatry 57: 237-245.

Wen L, Lu Y-S, Zhu X-H, Li X-M, Woo R-S, Chen Y-J et al (2010). Neuregulin 1 regulates pyramidal neuron activity via ErbB4 in parvalbumin-positive interneurons. Proc Natl Acad Sci USA 107: 1211-1216.

Woo TU, Miller JL, Lewis DA (1997). Schizophrenia and the parvalbumin-containing class of cortical local circuit neurons. Am J Psychiatry 154: 1013-1015.

Zhang ZJ, Reynolds GP (2002). A selective decrease in the relative density of parvalbumin-immunoreactive neurons in the hippocampus in schizophrenia. Schizophr Res 55: 1-10.

Supplementary Information accompanies the paper on the Neuropsychopharmacology website (http://www.nature.com/npp) 